\title{
Incorporation of natural colorants obtained from edible flowers in yogurts
}

\author{
Tânia C.S.P. Pires ${ }^{\mathrm{a}, \mathrm{b}}$, Maria Inês Dias ${ }^{\mathrm{a}}$, Lillian Barros ${ }^{\mathrm{a}}$, João C.M. Barreira ${ }^{\mathrm{a}}$, \\ Celestino Santos-Buelga ${ }^{\mathrm{b}}$, Isabel C.F.R. Ferreira ${ }^{\mathrm{a}, *}$ \\ a Centro de Investigação de Montanha (CIMO), Instituto Politécnico de Bragança, Campus de Santa Apolónia, 5300-253 Bragança, Portugal \\ ${ }^{\mathrm{b}}$ Grupo de Investigación en Polifenoles (GIP-USAL), Facultad de Farmacia, Universidad de Salamanca, Campus Miguel de Unamuno s/n, 37007 Salamanca, Spain
}

\section{A R T I C L E I N F O}

\section{Keywords:}

Natural colorants

Yogurt

Chemical composition

Shelf-life stability

\begin{abstract}
A B S T R A C T
The substitution of artificial dyes by natural colouring agents is among the top concerns of food industry to fulfil current consuming trends, justifying the prospection of novel natural sources of these compounds. Herein, the hydrophilic extracts from rose, cornflower and dahlia were tested as potential substitutes to E163 (anthocyanin extract). Besides comparing the colouring capacity, the potential occurrence of changes in the chemical composition of yogurts (nutritional parameters, free sugars and fatty acids) was also assessed throughout storage (up to 7 days) and compared with a "blank" (free of any additive) yogurt formulation. In general, yogurts prepared with flower extracts, presented similar nutritional value and free sugars profile to those prepared with E163 and to the "blank" yogurt. Nevertheless, rose extract turned out to be the most suitable alternative to E163 as these two groups of yogurts had similar nutritional composition, free sugars and fatty acids composition, besides presenting close scores in colour parameters.
\end{abstract}

\section{Introduction}

Fermented milk is a dairy product processed by lactic fermentation, which ends up by coagulating milk casein due to the acidification process ( $\mathrm{pH}$ values around 4.6). Among different fermented dairy products, yogurt is certainly one of the most popular, being widely consumed all over the world due to its organoleptic and nutritional properties (Arioui, Ait Saada, \& Cheriguene, 2017; Caleja et al., 2016).

Some yogurt formulations are prepared using specific additives, such as exemplified by colorants. However, the recent concerns about the safety of artificial colorants in food products, has encouraged the development and application of natural colorants, which are generally considered safer than artificial ones (Pop, Lupea, Popa, \& Gruescu, 2010). Anthocyanins are authorised food colorants (E163 in EU) and have previously been evaluated by the Joint FAO/WHO Expert Committee on Food Additives (JECFA) in 1982 and by the EU Scientific Committee for Food (SCF) in 1975 and 1997 (Pop et al., 2010; Rodriguez-Amaya, 2016). Anthocyanins are water-soluble pigments isolated from plants, being responsible for the blue, purple, and red colour of many plant tissues. These phenolic compounds are widely found in fruits (especially berries), as well as flowers and leaves, mainly linked to sugar units. Their sugar-free counterparts (anthocyanidins) are based on the flavylium cation, which might present different substitution patterns originating the diversity of anthocyanidins found in nature (Hidalgo \& Almajano, 2017). Among the 17 natural anthocyanidins, cyanidin, delphinidin, petunidin, peonidin, pelargonidin and malvidin, are the major forms in most species (Hidalgo \& Almajano, 2017).

In what concerns the application of anthocyanins in food products, there are some previous reports describing the incorporation of rose (Rosa damascena) petals extracts in yogurt (e.g., Chanukya \& Rastogi, 2016). Owing to the previously evidenced suitability of $R$. damascena as a colour ring agent in yogurt, we selected that species as one of the plant sources of anthocyanins to be incorporated in the yogurt formulations prepared in the lab. Likewise, we selected the flowers of Centaurea cyanus L. (cornflower), mainly due to its richness in cyanidin 3-O-(6-O-succinylglucoside)-5-O-glucoside (Takeda et al., 2005), but also in other bioactive phenolic compounds such as apigenin-glucuronide (Pires, Dias, Barros, \& Ferreira, 2017) and Dahlia mignon (dahlia), which also presents a rich composition in different phenolic compounds like naringenin-3-O-glucoside, kaempferol-pentosyl-rhamnosyl-hexoside or apigenin-hexoside (Deguchi, Ohno, Hosokawa, Tatsuzawa, \& Doi, 2013; Pires et al., 2018).

The selection and purchase of food products are greatly influenced by sensory expectations (Spence, Levitan, Shankar, \& Zampini, 2010). Visual perception deliver so called quality cues, perceived prior to actual consumption and give hints of the quality attributes that are apparent during the consumption (Jantathai, Sungsri-in, Mukprasirt, \&

\footnotetext{
* Corresponding author.

E-mail address: iferreira@ipb.pt (I.C.F.R. Ferreira).
} 
Duerrschmid, 2014; Spence et al., 2010). Colour plays an important role in the development of food preferences and sensory perception (Jantathai et al., 2014).

Nevertheless, colour is not important only in what concerns the product appearance. In fact, some colouring agents may have important functions beyond their primary effect. Anthocyanins, for instance, might have beneficial health effects due to their antioxidant, anti-inflammatory, anticancer, and anti-diabetic properties, thereby being of great interest to the food industry (Rodriguez-Amaya, 2016). However, it is also necessary to take into account that anthocyanins might degrade or react in food systems to form complex reaction products, leading to a mixture of products in addition to the parent anthocyanins (Rodriguez-Amaya, 2016). The intensity and stability of anthocyanins when used as food additives are influenced by $\mathrm{pH}$, structure, concentration, co-pigmentation and metal complexing, as well as temperature, light, oxygen, acetaldehyde, ascorbic acid, sugars and their degradation products, sulphur dioxide, amino acids and catechins. Still, when low $\mathrm{pH}$ conditions are maintained, anthocyanins are relatively stable (EFSA, 2013; Rodriguez-Amaya, 2016).

Accordingly, the aim of the present study was to develop a new colouring strategy in yogurt products using natural anthocyanin rich extracts obtained from edible flower petals of Dalia mignon, Centaurea cyanus L. and Rosa damascena "Alexandria" mixed with Rosa gallica "French" draft in Rosa canina. These flowers were firstly characterized and quantified regarding the anthocyanin content, thought an HPLCDAD-ESI/MS system. Additionally, the chromatic stability was evaluated by performing the evaluation studies (nutritional parameters, free sugars, fatty acids, anthocyanin content, and colour parameter) in yogurt formulation at two different periods (preparation day and after 7 days of storage).

\section{Materials and methods}

\subsection{Samples}

Dried commercial samples of petals of Dahlia mignon, rose resulting from $R$. damascena 'Alexandria' and $R$. gallica 'Francesa' draft in $R$. canina, and Centaurea cyanus L. were provided by RBR foods (Castro D'aire, Portugal).

In order to prepare the extracts, samples were reduced to powder (20 mesh) and were extracted by maceration $\left(25^{\circ} \mathrm{C}, 150 \mathrm{rpm}, 1 \mathrm{~h}\right)$ using a stirring plate (VELP scientific, Keyland Court, NY, USA) by adding $1 \mathrm{~g}$ of dry material to $50 \mathrm{~mL}$ of distilled water. Afterwards, the mixture was filtered through Whatman filter paper No. 4, frozen and lyophilized. The lyophilized extracts obtained were used as natural additives.

\subsection{Anthocyanin compounds identification by HPLC-DAD-ESI/MS}

The chromatographic data of anthocyanin compounds were acquired from a Dionex Ultimate 3000 system (Thermo Scientific, San Jose, CA, USA), coupled to diode array, using $520 \mathrm{~nm}$ as preference wavelength, and to a mass spectrometer (MS, Linear Ion Trap LTQ XL mass spectrometer, Thermo Finnigan, San Jose, CA, USA) operating in the positive mode (Gonçalves et al., 2017). Retention times, UV-Vis and mass spectra were compared with available standards and with literature data to identify the anthocyanin's. Calibration curves of the available anthocyanin standards were constructed based on the UV signal to perform quantitative analysis, in case of an unavailable commercial standards, the compounds were quantified via the calibration curves of the most similar available standards. The results were expressed as $\mu \mathrm{g} / \mathrm{g}$ of dry extract.

\subsection{Fortification of yogurts with natural and commercial colorant additives}

\subsubsection{Incorporation process}

The base formulation yogurts (fat $3.8 \%$; protein $5.0 \%$ and carbohydrates $4.7 \%$ ) were purchased at the local market. Five groups (three samples/group) of yogurts (70 $\mathrm{g}$ each) were prepared, with three replicates of each: i) control samples (BY); ii) yogurts with commercial colorant, E 163 (AY); iii) yogurts with rose petals extract (RY); iv) yogurts with Centaurea cyanus L. petals extract (CY); v) yogurts with Dahlia mignon petals extract (DY). All colorants were added to a portion of $70 \mathrm{~g}$ of yogurt and were prepared in duplicate. The E163 colorant was added at a $0.02 \%$ concentration; in the case of yogurts added with petals extracts, slightly higher concentrations of each extract $(0.05 \%$ for dahlia extract; $0.15 \%$ for rose extract; $0.10 \%$ for centaurea extract) were added (the quantity was added until an evident change in colour was obtained).

\subsubsection{Nutritional and chemical composition}

The proximate composition was determined according to AOAC procedures (AOAC, 2016), including protein (991.02), crude fat (989.05) and ash (935.42) contents. Crude protein $(\mathrm{N} \times 6.25)$ was determined by the Kjeldahl method; ash content was estimated by subjecting the sample to incineration at $600 \pm 15{ }^{\circ} \mathrm{C}$ for $5 \mathrm{~h}$, while crude fat was determined using a Soxhlet apparatus with petroleum ether as recycling solvent and total carbohydrate was estimated by difference. The total energy was calculated using the following equation: Energy $(\mathrm{kcal})=4 \times(\mathrm{g}$ protein $+\mathrm{g}$ carbohydrates $)+9 \times(\mathrm{g}$ fat $)$.

Free sugars were determined by high performance liquid chromatography coupled to a refraction index detector (HPLC-RI; Knauer, Smartline system 1000, Berlin, Germany), using melezitose as an internal standard. All the mentioned procedures were previously described by the authors (Barros, Pereira, \& Ferreira, 2013; Dias et al., 2015).

The fatty acids were determined by gas chromatography coupled with a flame ionization detector (GC-FID/capillary column, DANI model GC 1000, Contone, Switzerland), a split/splitless injector and a Macherey-Nagel column. The identification of fatty acids was performed by comparing the relative retention times of FAME peaks from samples with commercial standards (Barros et al., 2013; Dias et al., 2015).

Anthocyanins were determined in the yogurt sample by extracting $3 \mathrm{~g}$ of dry yogurt with water at $25^{\circ} \mathrm{C}, 150 \mathrm{rpm}$ during $1 \mathrm{~h}$, followed by filtration through a Whatman filter paper No. 4 . The remaining residue was re-extracted with an additional portion of water mixture, stored at $-20^{\circ} \mathrm{C}$ and lyophilized for further analysis. The lyophilized extracts were analysed using the HPLC-DAD-ESI/MS system mentioned above.

\subsection{Physico-chemical parameters}

The colour was measured in triplicate for each sample using a colorimeter (model CR-400, Konica Minolta Sensing Inc., Tokyo, Japan). The CIE $L^{*}, a^{*}$ and $b^{*}$ colour space values were registered using a data software "Spectra Magic Nx" (version CM-S100W 2.03.0006), using the illuminant $\mathrm{C}$ and diaphragm aperture of $8 \mathrm{~mm}$ (Fernandes et al., 2012). The $\mathrm{pH}$ values of the samples was measured directly with a HI 99161 pH-meter (Hanna Instruments, Woonsocket, Rhode Island, USA).

\subsection{Statistical analysis}

All statistical tests were performed at a 5\% significance level using IBM SPSS Statistics for Windows, version 22.0. (IBM Corp., Armonk, NY, USA).

Data were expressed as mean \pm standard deviation, maintaining the significant numbers allowed by the magnitude of the corresponding standard deviation.

An analysis of variance (ANOVA) with type III sums of squares was performed using the general linear model (GLM) procedure to compare the parameters evaluated in the prepared yogurts. The dependent variables were analysed using 2-way ANOVA with the factors "yogurt formulation" (YF) and "storage" (SE). When a statistically significant 
interaction was detected among the two factors, their effect was evaluated by checking estimated marginal means plots for all levels of each factor. On the contrary, if no statistical significant interaction was found, means were compared using Tukey's multiple comparison test, after verifying the homogeneity of variances through Levene's test.

In addition, a linear discriminant analysis (LDA) was used to have a better understanding about the YF overall effect. A stepwise technique was applied, considering the Wilks' $\Lambda$ test with the usual probabilities of $F$ (3.84 to enter and 2.71 to be removed) for variable selection. Only variables with a statistically significant classification performance $(p<0.050)$ were maintained by the statistical model. The significant independent variables were selected following the stepwise method of LDA. This procedure is based in sequential forward selection and backward elimination steps, where the inclusion of a new variable requires verifying the significance of all previously selected variables (Zielinski et al., 2014). The main purpose was estimating the relationship between the single categorical dependent variables (yogurt formulations) and the quantitative independent variables (results obtained in the laboratorial assays). The LDA outputs allowed determining which independent variables contributed more to the differences in the average score profiles of different YF. A leaving-one-out cross validation procedure was carried out to assess the model performance.

\section{Results and discussion}

\subsection{Anthocyanin profile characterization}

Owing to the powerful colouring capacity of anthocyanins, these compounds were thoroughly characterized in the extracts obtained from the petals of each selected species. The extraction yields (mg of anthocyanin per $100 \mathrm{~g}$ of petals) obtained for each sample extract were: $\sim 53 \%$ for dahlia; $\sim 46 \%$ for rose; and $\sim 23 \%$ for centaurea samples.

Nine anthocyanin compounds were detected in dahlia, two in rose and eight in centaurea extracts. Peak characteristics, tentative identification and compound quantification are presented in Table 1. Cyanidin (Cy; peaks 1, 2, 3, 4, 6, 10, 11, 13, 15, and 17), pelargonidin (Pg; peaks $8,9,12,16$, and 18), and delphinidin (Dp; peaks 5 and 7) were identified as main aglycones, based on the observation of their characteristic fragments in $\mathrm{MS}^{2}$ spectra. As reviewed by Castañeda-Ovando, Pacheco-Hernández, Páez-Hernández, Rodríguez, and Galán-Vidal (2009), these non-methylated anthocyanidins are the most commonly found in flowers, being cyanidin derivatives the most abundant in the analysed samples.

The conjugated bonds of anthocyanins, the glycosylated form of anthocyanidins, result in red, blue, and purple-coloured plants (Khoo, Azlan, Tang, \& Lim, 2017). Several foods, like yoghurt, are considered healthy, but they lack important components such as phenolic compounds. Therefore, the incorporation of plant extracts rich in anthocyanins in these fermented products might impart a desirable red colour, while enhancing their potential health effect (Mourtzinos et al., 2018).

Before incorporating the flower extracts in yogurts, their profiles in anthocyanins were thoroughly characterized. Peak $\mathbf{1}$, detected in rose and centaurea samples, was positively identified as cyanidin 3,5-di-Oglucoside based on the HPLC-DAD-MS results and comparison with our database library. This compound was already described as the main anthocyanin in petals of $R$. damascena (Velioglu \& Mazza, 1991) and $R$. hybrida (Lee, Lee, \& Choung, 2011) used with edible purposes, as well as in flowers from different Centaurea species (Mishio, Takeda, \& Iwashina, 2015), highlighting its suitability to be incorporated in yogurt formulations. Peak 2, found in rose samples, was also positively identified as cyanidin-3-O-glucoside according with its retention time and mass spectral data by comparison with a standard. The presence of this reddish-purple anthocyanin was also reported in rose hips $(R . c a-$ nina) previously Hvattum (2002).

Peak $4\left([\mathrm{M}]^{+}\right.$at $\left.m / z 711\right)$ was the majority anthocyanin in centaurea samples. Its $\mathrm{MS}^{2}$ spectra yielded fragments at $m / z 549(-162$ $\mathrm{mu}$, loss of a hexose), 449 ( $-262 \mathrm{mu}$, loss of succinylhexose) and 287 (cyanidin), coherent with an identity as Cy-3-O-(6"-succinylglucoside)5-O-glucoside, a compound consistently identified in centaurea flowers also referred to as centaurocyanin (Mishio et al., 2015; Kôsaku; Takeda \& Tominaga, 1983), and whose combination with a flavone glycoside

Table 1

Retention time (Rt), wavelengths of maximum absorption in the visible region ( $\left.\lambda_{\max }\right)$, mass spectral data, tentative identification, and quantification of anthocyanins in dahlia, rose, and centaurea extracts. Results are presented as mean \pm standard deviation.

\begin{tabular}{|c|c|c|c|c|c|c|}
\hline Peak & Rt (min) & $\lambda_{\max }(\mathrm{nm})$ & Molecular ion $(m / z)$ & $\operatorname{MS}^{2}(m / z)$ & Tentative identification & Quantification ( $\mu \mathrm{g} / \mathrm{g}$ extract) \\
\hline 1 & 11.5 & 514 & 611 & $449(10), 287(100)$ & Cyanidin 3,5-di-O-glucoside $\mathrm{A}^{\mathrm{A}}$ & $13.19 \pm 0.01$ \\
\hline 2 & 18.5 & 516 & 449 & $287(100)$ & Cyanidin-3-O-glucoside $^{\mathrm{A}}$ & $0.131 \pm 0.004$ \\
\hline \multicolumn{7}{|c|}{ Centaurea } \\
\hline 1 & 11.7 & 512 & 611 & $449(5), 287(100)$ & Cyanidin 3,5-di-O-glucoside ${ }^{\mathrm{A}}$ & $5.5 \pm 0.2$ \\
\hline 3 & 18.03 & 516 & 697 & $535(62), 449(8), 287(46)$ & Cyanidin 3-O-(6"-malonylglucoside)-5-O-glucoside ${ }^{\mathrm{A}}$ & $6.2 \pm 0.3$ \\
\hline 4 & 20.38 & 516 & 711 & $549(3), 449(48), 287(100)$ & Cyanidin 3-O-(6"-succinylglucoside)-5-O-glucoside ${ }^{\mathrm{A}}$ & $11.2 \pm 0.5$ \\
\hline 7 & 32.6 & 518 & 561 & $303(100)$ & Delphinidin-malonylhexoside $\mathrm{C}^{\mathrm{C}}$ & $\operatorname{tr}$ \\
\hline 8 & 38.1 & 501 & 695 & $609(9), 433(2), 271(82)$ & Pelargonidin 3-O-(6"-succinylglucoside)-5-O-glucoside & $0.18 \pm 0.01$ \\
\hline \multirow[t]{2}{*}{9} & 39.2 & 502 & 519 & $271(100)$ & Pelargonidin-malonylhexoside ${ }^{B}$ & $0.17 \pm 0.01$ \\
\hline & & & & & Total Anthocyanins & $26 \pm 1$ \\
\hline \multicolumn{7}{|c|}{ Dahlia } \\
\hline 10 & 11.6 & 516 & 449 & $287(100)$ & Cyanidin-hexoside ${ }^{\mathrm{A}}$ & $2.98 \pm 0.01$ \\
\hline 11 & 13.4 & 504 & 449 & $287(100)$ & Cyanidin-hexoside $^{\mathrm{A}}$ & $2.654 \pm 0.001$ \\
\hline 17 & 31.5 & 518 & 491 & $287(100)$ & Cyanidin-acetylhexoside $^{\mathrm{A}}$ & $0.33 \pm 0.02$ \\
\hline \multirow[t]{2}{*}{18} & 32.7 & 516 & 433 & $271(100)$ & Pelargonidin-hexoside $^{\text {B }}$ & $0.450 \pm 0.001$ \\
\hline & & & & & Total Anthocyanins & $18.8 \pm 0.2$ \\
\hline
\end{tabular}

tr-trace amounts; Standard calibration curves: A - cyanidin-3-O-glucoside $\left(y=243287 x-1 \mathrm{E}+06 ; R^{2}=0.995\right)$; B - pelargonidin-3-O-glucoside $(y=276117 x-$ 480418; $\left.R^{2}=0.9979\right)$; - delphinidin-3-O-glucoside $\left(y=557274 x+126.24 ; R^{2}=0.997\right)$. 
Table 2

Nutritional composition ( $\mathrm{g} / 100 \mathrm{~g}$ fresh weight) and energy values (kcal/100 $\mathrm{g}$ fresh weight) for different yogurt formulations (YF) and storage effect (SE). Results are presented as mean \pm standard deviation. ${ }^{\mathrm{a}}$

\begin{tabular}{|c|c|c|c|c|c|c|c|c|c|}
\hline & & Water & Fat & Protein & Ash & Carbohydrates & Galactose & Lactose & Energy \\
\hline \multirow[t]{6}{*}{ YF } & BY & $85.0 \pm 0.4$ & $3.3 \pm 0.1$ & $5.3 \pm 0.3$ & $0.79 \pm 0.03$ & $5.6 \pm 0.1$ & $0.69 \pm 0.01^{\mathrm{c}}$ & $4.7 \pm 0.1$ & $73 \pm 2$ \\
\hline & RY & $84.8 \pm 0.4$ & $3.3 \pm 0.2$ & $5.3 \pm 0.2$ & $0.85 \pm 0.01$ & $5.8 \pm 0.2$ & $0.71 \pm 0.04^{\mathrm{bc}}$ & $4.7 \pm 0.2$ & $74 \pm 3$ \\
\hline & DY & $85.0 \pm 0.1$ & $3.4 \pm 0.1$ & $5.4 \pm 0.1$ & $0.86 \pm 0.02$ & $5.4 \pm 0.1$ & $0.71 \pm 0.01^{\mathrm{b}}$ & $4.8 \pm 0.1$ & $73 \pm 1$ \\
\hline & $\mathrm{CY}$ & $84.8 \pm 0.1$ & $3.2 \pm 0.1$ & $5.4 \pm 0.1$ & $0.86 \pm 0.02$ & $5.7 \pm 0.1$ & $0.76 \pm 0.02^{\mathrm{a}}$ & $4.8 \pm 0.1$ & $74 \pm 1$ \\
\hline & AY & $84.9 \pm 0.2$ & $3.4 \pm 0.1$ & $5.3 \pm 0.1$ & $0.82 \pm 0.02$ & $5.5 \pm 0.1$ & $0.72 \pm 0.02^{\mathrm{b}}$ & $4.9 \pm 0.1$ & $74 \pm 1$ \\
\hline & ANOVA $p$-value $(\mathrm{n}=18)^{\mathrm{b}}$ & 0.083 & 0.001 & 0.039 & $<0.001$ & $<0.001$ & $<0.001$ & $<0.001$ & 0.632 \\
\hline \multirow[t]{3}{*}{ SE } & 0 days & $85.0 \pm 0.2$ & $3.3 \pm 0.1$ & $5.3 \pm 0.2$ & $0.84 \pm 0.04$ & $5.6 \pm 0.2$ & $0.73 \pm 0.03$ & $4.8 \pm 0.1$ & $73 \pm 1$ \\
\hline & 7 days & $84.8 \pm 0.3$ & $3.4 \pm 0.1$ & $5.4 \pm 0.1$ & $0.84 \pm 0.03$ & $5.6 \pm 0.2$ & $0.71 \pm 0.03$ & $4.8 \pm 0.1$ & $74 \pm 2$ \\
\hline & ANOVA $p$-value $(\mathrm{n}=45)^{\mathrm{c}}$ & 0.056 & 0.061 & 0.119 & 0.763 & 0.258 & 0.100 & 0.408 & 0.081 \\
\hline $\mathrm{YF} \times \mathrm{SE}$ & $p$-value $(\mathrm{n}=90)^{\mathrm{d}}$ & $<0.001$ & $<0.001$ & $<0.001$ & $<0.001$ & $<0.001$ & 0.272 & $<0.001$ & $<0.001$ \\
\hline
\end{tabular}

${ }^{a}$ Results are reported as mean values of each YF, aggregating results from 0 to 7 days, and mean values of SE, combining all YF.

b If $p<0.05$, the corresponding parameter presented a significantly different value for at least one YF.

c If $p<0.05$, the corresponding parameter presented a significant difference among stored and non-stored yogurts.

${ }^{\mathrm{d}}$ In this table, the interaction among factors was significant in all cases; thereby no multiple comparisons could be performed.

Table 3

Physicochemical parameters (CIE $L^{*}, a^{*}$ and $b^{*}$ and $\mathrm{pH}$ values) for different yogurt formulations (YF) and storage effect (SE). Results are presented as mean \pm standard deviation. ${ }^{\mathrm{a}}$

\begin{tabular}{|c|c|c|c|c|c|}
\hline & & $L^{*}$ & $a^{*}$ & $b^{*}$ & $\mathrm{pH}$ \\
\hline \multirow[t]{6}{*}{ YF } & BY & $93 \pm 1$ & $-3.5 \pm 0.1$ & $9.8 \pm 0.4$ & $4.3 \pm 0.1$ \\
\hline & RY & $88 \pm 1$ & $2.2 \pm 0.1$ & $9.0 \pm 0.3$ & $4.3 \pm 0.1$ \\
\hline & DY & $84 \pm 1$ & $2.1 \pm 0.3$ & $17.7 \pm 0.4$ & $4.4 \pm 0.1$ \\
\hline & CY & $90 \pm 1$ & $-1.1 \pm 0.2$ & $9.5 \pm 0.5$ & $4.2 \pm 0.1$ \\
\hline & $\mathrm{AY}$ & $89 \pm 1$ & $3.1 \pm 0.5$ & $6.5 \pm 0.5$ & $4.8 \pm 0.1$ \\
\hline & $\begin{array}{l}\text { ANOVA } p \text {-value } \\
(\mathrm{n}=18)^{\mathrm{b}}\end{array}$ & $<0.001$ & $<0.001$ & $<0.001$ & $<0.001$ \\
\hline \multirow[t]{3}{*}{ SE } & 0 days & $88 \pm 3$ & $1 \pm 3$ & $10 \pm 3$ & $4.4 \pm 0.2$ \\
\hline & 7 days & $89 \pm 3$ & $0 \pm 2$ & $11 \pm 3$ & $4.4 \pm 0.2$ \\
\hline & $\begin{array}{l}\text { ANOVA } p \text {-value } \\
(\mathrm{n}=45)^{\mathrm{c}}\end{array}$ & 0.056 & 0.250 & 0.312 & 0.946 \\
\hline $\mathrm{IF} \times \mathrm{ST}$ & $p$-value $(\mathrm{n}=90)^{\mathrm{d}}$ & $<0.001$ & $<0.001$ & $<0.001$ & 0.867 \\
\hline
\end{tabular}

${ }^{\mathrm{a}}$ Results are reported as mean values of each $\mathrm{YF}$, aggregating results from 0 to 7 days, and mean values of SE, combining all YF.

${ }^{\mathrm{b}}$ If $p<0.05$, the corresponding parameter presented a significantly different value for at least one YF.

${ }^{\mathrm{c}}$ If $p<0.05$, the corresponding parameter presented a significant difference among stored and non-stored yogurts.

${ }^{\mathrm{d}}$ In this table, the interaction among factors was significant in all cases; thereby no multiple comparisons could be performed.

and metal ions give rise to protocyanin, a stable complex pigment considered to be the main responsible for the blue colour of Centaurea cyanus flowers (Kosaku Takeda et al., 2005). This compound could have interesting colouring properties to be used as a natural additive in food products. Similarly, mass spectral characteristics of peak 3 , with a molecular ion $[\mathrm{M}]^{+}$at $m / z 697$ and $\mathrm{MS}^{2}$ fragments at $m / z 535(-162$ $\mathrm{mu}$, loss of a hexose), 449 ( $-248 \mathrm{mu}$, loss of malonylhexose) and 287 (cyanidin), allowed tentatively assigning it as Cy-3-O-(6"-malonylglucoside)-5-O-glucoside owing to its previous identification in flowers from different Centaurea species (Mishio et al., 2015). Peak 6 $\left([\mathrm{M}]^{+}\right.$at $m / z 463$ ) was another cyanidin derivative, tentatively identified as $\mathrm{Cy}$-O-glucuronide based on the loss of $176 \mathrm{mu}$ (a glucuronyl moiety) to yield the unique $\mathrm{MS}^{2}$ product ion at $m / z 287$.

Peaks 8 and 9 in centaurea samples were associated to pelargonidin derivatives based on their characteristic absorption spectra showing $\lambda_{\max }$ at $501 \mathrm{~nm}$ and the fragment ion observed at $m / z 271(\mathrm{Pg})$. Peak 8 $\left([\mathrm{M}]^{+}\right.$at $m / z$ 695), with similar fragmentation behaviour as peak 4 , was identified as Pg-3-O-(6"-succinylglucoside)-5-O-glucoside, previously described in Centaurea cyanus flowers by Kosaku Takeda, Kumegawa, Harborne, and Self (1988). Peak 9 ([M] ${ }^{+}$at $m / z$ 519) was tentatively assigned as a $\mathrm{Pg}$-O-malonylhexoside based on the loss of 248 mu (malonylhexoside) to yield the aglycone ion at $m / z$ 271. Pelargonidin differs from most anthocyanidins as it might provide an orange hue to flowers and red to some of the fruits and berries (Jaakola, 2013; Khoo et al., 2017), having also demonstrated a notable anti-inflammatory effect (Duarte et al., 2018). In a similar way, peak 7 ([M $]^{+}$ at $m / z 561$ ), yielding a unique $\mathrm{MS}^{2}$ fragment at $m / z 303(-248 \mathrm{mu})$ was associated to delphinidin- $O$-malonylhexoside, whereas peak 5 $\left([\mathrm{M}]^{+}\right.$at $\left.m / z 465\right)$ was assigned as a Dp-O-hexoside; a possible identity as Dp-3-O-glucoside was excluded by comparison with peak characteristics with our database library. Delphinidin appears as a purple pigment in the nature, and the blue hue of flowers is often due this pigment, which was previously reported for its anti-inflammatory, antioxidant, and anti-tumorigenic activities (Ko et al., 2015), making it specially interesting as an ingredient of innovative food formulations (Khoo et al., 2017).

Similar reasoning was applied to identify anthocyanins in dahlia samples as cyanidin (peaks 10, 11, 13, 15 and 17) and pelargonidin derivatives (peaks 12, 16 and 18), which were previously reported in dahlia flowers (Deguchi et al., 2013; Kosaku; Takeda, Harborne, \& Self, 1986; Yamaguchi et al., 1999). The presence of Pg-3,5-diglucoside in flowers of Dahlia variabilis was identified by Yamaguchi et al. (1999) and Deguchi et al. (2013), which could correspond to peak $16\left([\mathrm{M}]^{+}\right.$at $m / z 595$ ) in our samples. For the remaining compounds (peaks 10, 11, $12,13,15,17$, and 18), no conclusions about the precise identity of the anthocyanins could be obtained, and the glycoside moieties were assigned based on the mass losses observed in the MS ${ }^{2}$ spectra, as hexosides $(-162 \mathrm{mu})$, acetylhexosides $(-204 \mathrm{mu})$ or deoxyhexosylhexosides ( $-308 \mathrm{mu}$ ). Curiously, none of the observed peak losses indicates the presence of malonylglucosides, a type of derivatives usually reported in dahlia flowers (Deguchi et al., 2013; Kosaku; Takeda et al., 1986; Yamaguchi et al., 1999). Cy-acetylhexoside (peak 13) was the most abundant compound in dahlia, representing the main responsible for the coloration of this edible flowers. In addition to improve the sensory characteristics of yogurt, that cyanidin might be a promising antiglycation agent for preventing or ameliorating AGEs-mediated diabetic complications (Suantawee, Cheng, \& Adisakwattana, 2016). Finally, peak 14 presented a molecular ion $[\mathrm{M}]^{+}$at $m / z 431$ and a unique $\mathrm{MS}^{2}$ fragment at $m / z 269$, which could match the mass of methylapigeninidin, so that it might be associated to a methylapigeninidin-hexoside, a pigment reported in red sorghum (Wu \& Prior, 2005). Nevertheless, the absorption spectrum of peak 14 would not be coherent with such an identity, as the maximum absorption in the visible region of that compound should be expected around $470 \mathrm{~nm}$ (Awika, 2008; Yang, Dykes, \& Awika, 2014). Thus, the identity of this peak as a 3-deoxyanthocyanin is uncertain, although in case it is confirmed it would be the first description of this type of pigments in dahlia flowers.

In general, these flowers have a great potential to be used as natural 


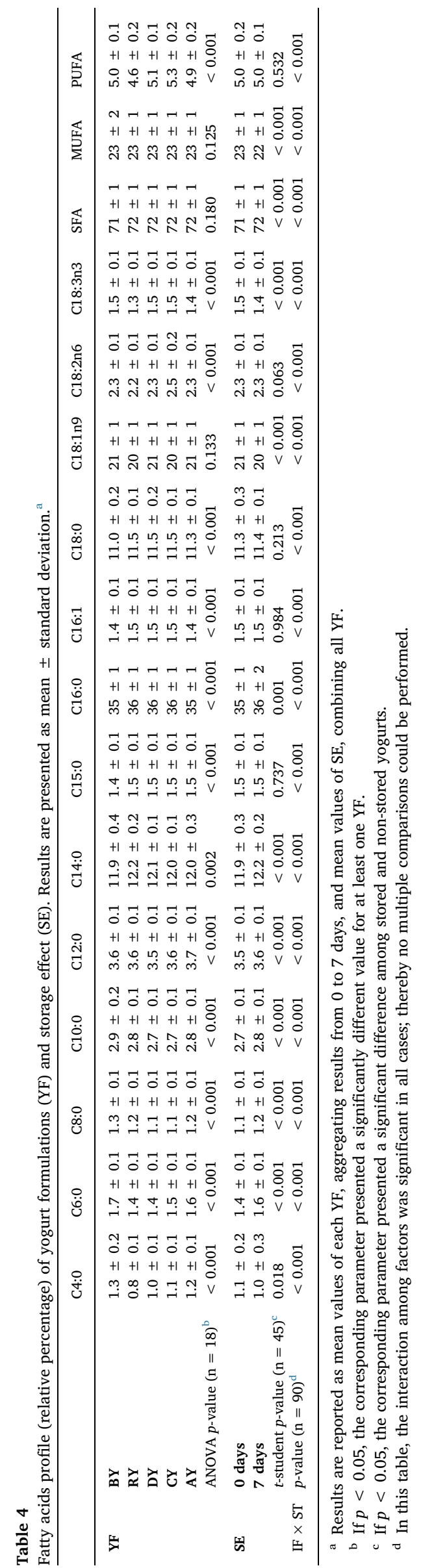

colorants, being an excellent source of anthocyanins to develop innovative products with new sensorial and bioactive characteristics.

\subsection{Characterization of different fortified yogurts}

Natural additives are generally considered as producing no harmful effects on consumers' health, contrarily to some artificial compounds (Carocho, Barreiro, Morales, \& Ferreira, 2014). Nevertheless, the acceptability of these products is highly dependent on their appearance and rheological properties (Caleja et al., 2016; Santillán-Urquiza, Méndez-Rojas, \& Vélez-Ruiz, 2017). In what concerns yogurt, similarly to several other food products, colour is a determining factor. Bearing this in mind, different plant species were selected as potential sources of colourants to be incorporated in yogurt. Yogurts prepared with different flower extracts were compared with each other and also with yogurts added with a commercial anthocyanin extract (E163, authorised by EFSA). In addition, a set of yogurts were used exactly as bought (free of any colouring agent), functioning as the "blank" yogurt control.

Besides comparing different yogurt formulations (YF), their stability throughout storage was also evaluated, specifically by performing the same evaluation assays on the preparation day and after 7 days of storage (SE).

Since the effect of each factor (YF or SE) might be affected by the second factor level (i.e., different storage effects according on each YF, or vice versa), the interaction ( $\mathrm{YF} \times \mathrm{SE}$ ) was also evaluated. In all cases where a significant interaction was found $(p<0.050)$, the multiple comparisons could not be performed. In those cases, the overall conclusions were obtained from the corresponding estimated marginal means (EMM) plots.

Starting by analysing the results for nutritional parameters (Table 2), a significant interaction among YF and SE (YF $\times$ SE) was found in all cases, thereby indicating that each YF reacted differently to storage. Considering each factor individually, YF-related differences were significant in most cases, except water and energy, while SE had no significant effect in any case. In either case, the nutritional profile is very similar among all tested samples, with water as the main component $(\approx 85 \mathrm{~g} / 100 \mathrm{~g}$ ), followed by carbohydrates (slightly higher in RY and $\mathrm{CY}$ and lower in DY) and protein (a bit higher in CY and lower in $\mathrm{RY}$ ), both corresponding to $\approx 5.5 \mathrm{~g} / 100 \mathrm{~g}$ ), fat $(\approx 3.2 \mathrm{~g} / 100 \mathrm{~g}$ in CY to $3.4 \mathrm{~g} / 100 \mathrm{~g}$ DY and $\mathrm{AY})$ and ash $(<0.9 \mathrm{~g} / 100 \mathrm{~g}$ in all yogurts). This profile resulted in energy values around $74 \mathrm{kcal} / 100 \mathrm{~g}$ in all cases. Actually, owing to the low quantity of colorant added, it was not expectable to have differences of high magnitude among different YF, particularly in what concerns fat amounts (the flower extracts were prepared with water). Nevertheless, the plant species used in the extraction procedures had different nutritional composition (Pires et al., 2017), causing some minor changes in the corresponding yogurts. Even so, these results validate the maintenance of the nutritional quality of natural yogurt (herein identified as BY).

In what concerns individual sugars, lactose was the main compound ( $\approx 4.8 \mathrm{~g} / 100 \mathrm{~g}$, with slightly higher values in AY). Minor levels of galactose were also quantified, varying form the maximum values detected in CY $(0.76 \mathrm{~g} / 100 \mathrm{~g})$ to the lowest in BY $(0.69 \mathrm{~g} / 100 \mathrm{~g})$.

More significant differences were, as observable in Table 3 , obtained in the case of colour parameters, which is in line with the main purpose of this work. Yogurts free of any additive (BY) showed the highest $L^{*}$ values, followed by CY, AY, RY and DY. On the contrary, BY presented the lowest $a^{*}$ values, while AY, RY and DY reached the highest (without significantly different values among them). On the other hand, the absence of significant differences for $a^{*}$ values among $\mathrm{AY}, \mathrm{RY}$ and DY, indicate that rose and dahlia extracts might be potential alternatives to E163.

Fatty acids profiles, especially for their potential usefulness as indicators of suitable conservation conditions, were also characterized (Barreira, Pereira, Oliveira, \& Ferreira, 2010; Pereira et al., 2016). All fatty acids quantified in relative percentages above $1 \%$ are presented in 


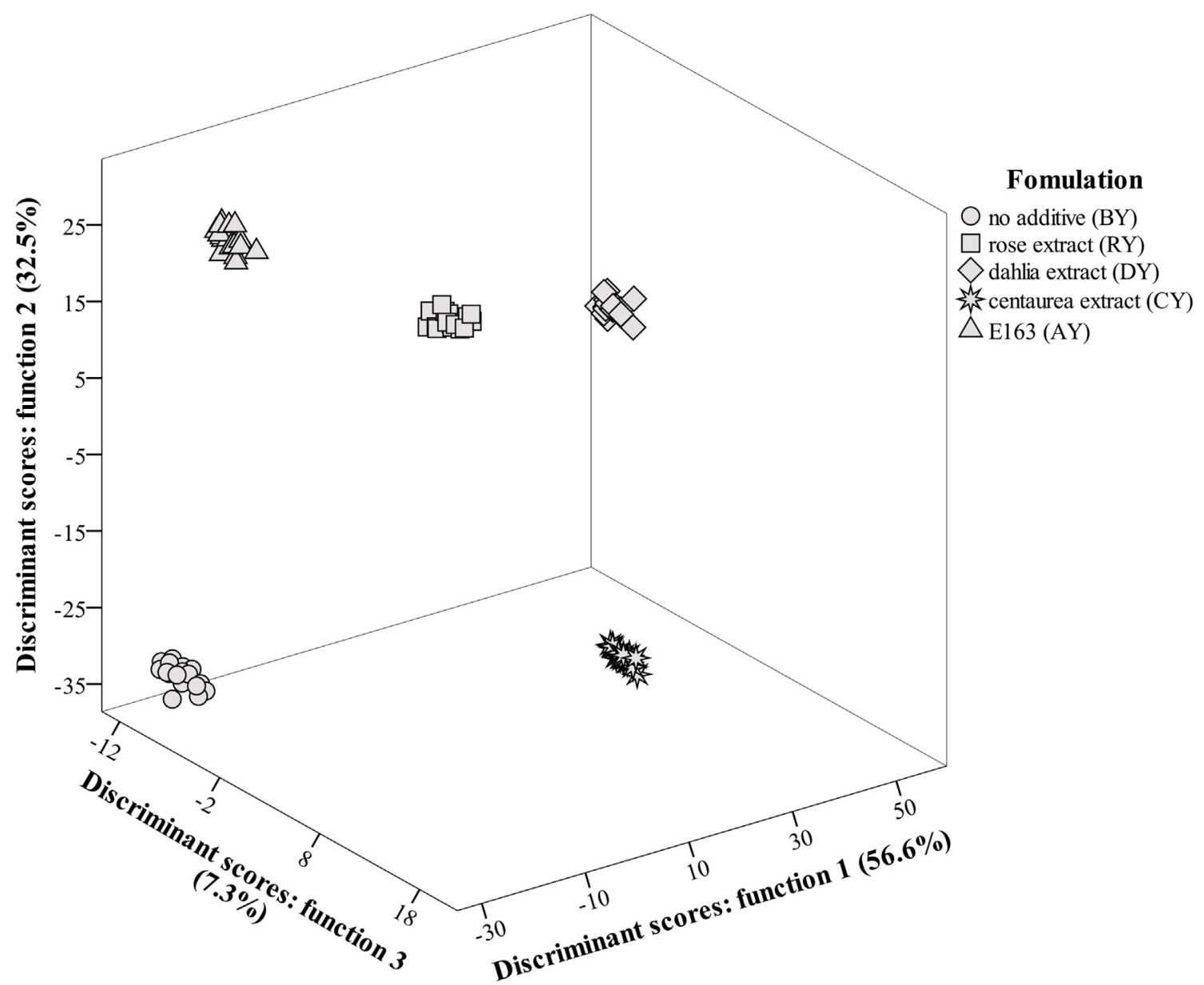

Fig. 1. Three-dimensional distribution of YF markers according to the canonical discriminant functions coefficients defined from different yogurt parameters.

Table 4, but the complete profiles included also C11:0, C13:0, C14:1, $\mathrm{C} 17: 0, \mathrm{C} 17: 1, \mathrm{C} 18: 3 \mathrm{n} 6, \mathrm{C} 20: 0, \mathrm{C} 20: 1, \mathrm{C} 20: 4 \mathrm{n} 6, \mathrm{C} 20: 5 \mathrm{n} 3, \mathrm{C} 22: 0, \mathrm{C} 23: 0$, C24:0 (however, all fatty acids were included in the Linear Discussion Analysis discussed in the next section).

Since milk was the main source of fatty acids in yogurt, and bearing in mind, once again, that the added extracts were aqueous, the high similarity among YF is coherent. Nevertheless, C18:1n9 $(p=0.133)$, SFA $(p=0.180)$ and MUFA $(p=0.125)$ were the only cases with no significant differences among tested YF, most likely because the added extracts might have different effectiveness in preventing the oxidation of specific fatty acids throughout time.

Since the interaction among factors $(\mathrm{YF} \times \mathrm{SE})$ the next conclusions were obtained from the EMM plots (data not shown): BY presented higher percentages of $\mathrm{C} 4: 0(1.3 \%), \mathrm{C} 6: 0(1.7 \%), \mathrm{C} 8: 0(1.3 \%)$, and C10:0 (2.9\%), while C15:0 (1.5\%), C16:1 (1.5\%), C18:0 (11.5\%), C18:2n6 (2.5\%) and PUFA (5.3\%) showed the highest values in CY. Yogurts prepared with rose extract (RY), on the other hand, had the highest percentages of C14:0 (12.2\%) and C16:0 (36\%), whilst C12:0 was slightly higher in AY (3.7\%).

In what concerns SE effect, almost all tabled fatty acids showed significant differences, except in the cases of C15:0 $(p=0.737), \mathrm{C} 16: 1$ $(p=0.984), \mathrm{C} 18: 0 \quad(p=0.213), \mathrm{C} 18: 2 \mathrm{n} 6 \quad(p=0.063)$ and PUFA $(p=0.532)$. In stored samples, C6:0, C8:0, C10:0, C12:0, C14:0, C16:0 and SFA were quantified in higher percentages, while C4:0, C18:1n9, C19:3n3 and MUFA tended to present higher values in non-stored samples, thereby generally corroborating the higher resistance of saturated forms to storage.

\subsection{Linear discriminant analysis}

Despite the statistical significance of differences among different YF, we decided to verify if the magnitude of the detected differences was high enough to discriminate each YF. Accordingly, a linear discriminant analysis (LDA) was applied to find the variables with highest contribution to discriminate each YF.

The first three discriminant functions included $97.7 \%$ (first function: $61.4 \%$; second function: $30.0 \%$; third function: $6.3 \%$ ) of the observed variance (Fig. 1). From the 41 variables under analysis, the discriminant model selected $b^{*}, a^{*}, L^{*}, \mathrm{pH}, \mathrm{C} 4: 0, \mathrm{C} 8: 0, \mathrm{C13:0,}$ C16:1, C17:1, C18:3n3, C18:3n6, C20:1, C20:4n6, C20:5n3, C23:0, C24:0 and PUFA as those having discriminant ability, which clearly indicates that fatty acids and colour parameters were the variables with highest dissimilarity among the prepared YF.

In what concerns the correlations among functions and variables, function 1 was highly correlated with $b^{*}$ and $L^{*}$, placing markers corresponding to DY and BY in the farthest positions due to their differences in both parameters (the highest $b^{*}$ value was measured in DY, while the maximum $L^{*}$ was measured in BY). Function 2, in turn, was mostly correlated with $a^{*}$, mostly separating markers corresponding to AY and RY (positive end of the axis) from BY (negative end of the axis). Function 3 also contributed to separate the markers of each YF, being especially effective in separating BY and CY. Owing to the higher proximity of their markers according to the three plotted discriminant functions RY and AY showed the highest similarity among the assayed parameters.

In the performed LDA, the classification performance was $100 \%$ accurate, either for original grouped cases, as well as for the cross- 
validated grouped cases.

\section{Conclusion}

Overall, the natural extracts with highest potential as alternatives to E163 resulted to be RY, considering the main purpose of colouring yogurts in the yellow-orange series. In addition to the provided colour, these groups of yogurts ( $\mathrm{AY}$ and $\mathrm{RY}$ ) showed very similar nutritional value, free sugars and fatty acids composition.

\section{Conflicts of interest}

The authors declare that they have no conflicts of interest.

\section{Acknowledgements}

The authors are grateful to the Foundation for Science and Technology (FCT, Portugal) for financial support to CIMO (strategic project UID/AGR/00690/2013), to REQUIMTE (national funds and cofinanced by FEDER, under the Partnership Agreement PT2020), Tânia Pires (SFRH/BD/129551/2017) and João C.M. Barreira and L. Barros contracts. The GIP-USAL is financially supported by the Spanish Government through the project AGL2015-64522-C2-2-R. The authors are also grateful to FEDER-Interreg España-Portugal programme for financial support through the project 0377_Iberphenol_6_E; the European Structural and Investment Funds (FEEI) through the Regional Operational Program North 2020, within the scope of Project NORTE01-0145-FEDER-023289: DeCodE and Project Mobilizador Norte-010247-FEDER-024479: ValorNatural ${ }^{\varpi}$.

\section{References}

AOAC (2016). In W. George, \& J. Latimer (Eds.). Official methods of analysis of AOAC international - 20th edition(20th ed.). AOAC International,

Arioui, F., Ait Saada, D., \& Cheriguene, A. (2017). Physicochemical and sensory quality of yogurt incorporated with pectin from peel of Citrus sinensis. Food Sciences and Nutrition, 5(2), 358-364. https://doi.org/10.1002/fsn3.400.

Awika, J. M. (2008). Behavior of 3-deoxyanthocyanidins in the presence of phenolic copigments. Food Research International, 41(5), 532-538.

Barreira, J. C. M., Pereira, J. A., Oliveira, M. B. P. P., \& Ferreira, I. C. F. R. (2010). Sugars profiles of different chestnut (Castanea sativa Mill.) and almond (Prunus dulcis) cultivars by HPLC-RI. Plant Foods for Human Nutrition, 65(1), 38-43. https://doi.org/10. 1007/s11130-009-0147-7.

Barros, L., Pereira, C., \& Ferreira, I. C. F. R. (2013). Optimized analysis of organic acids in edible mushrooms from Portugal by ultra fast liquid chromatography and photodiode array detection. Food Analytical Methods, 6(1), 309-316. https://doi.org/10.1007/ s12161-012-9443-1.

Caleja, C., Barros, L., Antonio, A. L., Carocho, M., Oliveira, M. B. P. P., \& Ferreira, I. C. F. R. (2016). Fortification of yogurts with different antioxidant preservatives: A comparative study between natural and synthetic additives. Food Chemistry, 210, 262-268. https://doi.org/10.1016/j.foodchem.2016.04.114.

Carocho, M., Barreiro, M. F., Morales, P., \& Ferreira, I. C. F. R. (2014). Adding molecules to food, pros and cons: A review on synthetic and natural food additives. Comprehensive Reviews in Food Science and Food Safety, 13(4), 377-399. https://doi org/10.1111/1541-4337.12065.

Castañeda-Ovando, A., Pacheco-Hernández, M. de L., Páez-Hernández, M. E., Rodríguez, J. A., \& Galán-Vidal, C. A. (2009, April). Chemical studies of anthocyanins: A review. Food chemistry. Elsevierhttps://doi.org/10.1016/j.foodchem.2008.09.001.

Chanukya, B. S., \& Rastogi, N. K. (2016). A comparison of thermal processing, freeze drying and forward osmosis for the downstream processing of anthocyanin from rose petals. 40(6 OP-Journal of Food Processing \& Preservation. Dec 2016, Vol. 40 Issue 6, p1289, 8 p.), 1289. https://doi.org/10.1111/jfpp.12714.

Deguchi, A., Ohno, S., Hosokawa, M., Tatsuzawa, F., \& Doi, M. (2013). Endogenous posttranscriptional gene silencing of flavone synthase resulting in high accumulation of anthocyanins in black dahlia cultivars. Planta, 237(5), 1325-1335. https://doi.org/ 10.1007/s00425-013-1848-6.

Dias, M. I., Barros, L., Morales, P., Sánchez-Mata, M. C., Oliveira, M. B. P. P., \& Ferreira, I. C. F. (2015). Nutritional parameters of infusions and decoctions obtained from Fragaria vesca L. roots and vegetative parts. Lebensmittel-Wissenschaft und -TechnologieFood Science and Technology, 62(1), 32-38. https://doi.org/10.1016/j.lwt.2015.01. 034.

Duarte, L. J., Chaves, V. C., Nascimento, M. V. P., dos, S., Calvete, E., Li, M., et al. (2018). Molecular mechanism of action of Pelargonidin-3-O-glucoside, the main anthocyanin responsible for the anti-inflammatory effect of strawberry fruits. Food Chemistry, 247, 56-65. https://doi.org/10.1016/j.foodchem.2017.12.015.

E.F.S.A (2013). Scientific Opinion on the re-evaluation of anthocyanins (E 163) as a food additive. EFSA Journal, 11(4), 3145. https://doi.org/10.2903/j.efsa.2013.3145.

Fernandes, Â., Antonio, A. L., Barreira, J. C. M., Oliveira, M. B. P. P., Martins, A., \& Ferreira, I. C. F. R. (2012). Effects of gamma irradiation on physical parameters of Lactarius deliciosus wild edible mushrooms. Postharvest Biology and Technology, 74, 79-84. https://doi.org/10.1016/j.postharvbio.2012.06.019.

Gonçalves, G. A., Soares, A. A., Correa, R. C. G., Barros, L., Haminiuk, C. W. I., Peralta, R. M., et al. (2017). Merlot grape pomace hydroalcoholic extract improves the oxidative and inflammatory states of rats with adjuvant-induced arthritis. Journal of Functiona Foods, 33, 408-418.

Hidalgo, G.-I., \& Almajano, M. P. (2017). Red fruits: Extraction of antioxidants, phenolic content, and radical scavenging determination: A review. https://doi.org/10.3390/ antiox6010007.

Hvattum, E. (2002). Determination of phenolic compounds in rose hip (Rosa canina) using liquid chromatography coupled to electrospray ionisation tandem mass spectrometry and diode-array detection. Rapid Communications in Mass Spectrometry, 16(7), 655-662. https://doi.org/10.1002/rcm.622.

Jaakola, L. (2013). New insights into the regulation of anthocyanin biosynthesis in fruits. Trends in Plant Science, 18(9), 477-483. https://doi.org/10.1016/J.TPLANTS.2013. 06.003.

Jantathai, S., Sungsri-in, M., Mukprasirt, A., \& Duerrschmid, K. (2014). Sensory expectations and perceptions of austrian and Thai consumers: A case study with six colored Thai desserts. Food Research International, 64, 65-73. https://doi.org/10. 1016/j.foodres.2014.06.007.

Khoo, H. E., Azlan, A., Tang, S. T., \& Lim, S. M. (2017). Anthocyanidins and anthocyanins: Colored pigments as food, pharmaceutical ingredients, and the potential health benefits. Food \& Nutrition Research, 61(1), 1361779. https://doi.org/10.1080/ 16546628.2017.1361779.

Ko, H., Jeong, M.-H., Jeon, H., Sung, G.-J., So, Y., Kim, I., et al. (2015). Delphinidin sensitizes prostate cancer cells to TRAIL-induced apoptosis, by inducing DR5 and causing caspase-mediated HDAC3 cleavage. Oncotarget, 6(12), 9970-9984. https:// doi.org/10.18632/oncotarget.3667.

Lee, J. H., Lee, H.-J., \& Choung, M.-G. (2011). Anthocyanin compositions and biological activities from the red petals of Korean edible rose (Rosa hybrida cv. Noblered). Food Chemistry, 129(2), 272-278. https://doi.org/10.1016/J.FOODCHEM.2011.04.040.

Mishio, T., Takeda, K., \& Iwashina, T. (2015). Anthocyanins and other flavonoids as flower pigments from eleven Centaurea species. Natural Product Communications, 10(3), 447-450.

Mourtzinos, I., Prodromidis, P., Grigorakis, S., Makris, D. P., Biliaderis, C. G., \& Moschakis, T. (2018). Natural food colourants derived from onion wastes: Application in a yoghurt product. Electrophoresis, 1-28https://doi.org/10.1002/elps. 201800073.

Pereira, E., Barros, L., Barreira, J. C. M., Carvalho, A. M., Antonio, A. L., \& Ferreira, I. C. F. R. (2016). Electron beam and gamma irradiation as feasible conservation technologies for wild Arenaria Montana L.: Effects on chemical and antioxidant parameters. Innovative Food Science \& Emerging Technologies, 36, 269-276. https://doi.org/10. 1016/j.ifset.2016.07.012.

Pires, T. S. C. P., Dias, M. I., Barros, L., Calhelha, R. C., Alves, M. J., Oliveira, M. B. P. P., et al. (2018). Edible flowers as sources of phenolic compounds with bioactive potential. Food Research International, 105, 580-588.

Pires, T. C. S. P., Dias, M. I., Barros, L., \& Ferreira, I. C. F. R. (2017). Nutritional and chemical characterization of edible petals and corresponding infusions: Valorization as new food ingredients. Food Chemistry, 220, 337-343. https://doi.org/10.1016/j. foodchem.2016.10.026.

Pop, M., Lupea, A. X., Popa, S., \& Gruescu, C. (2010). Colour of bilberry (Vaccinium myrtillus fruits) extracts. https://doi.org/10.1080/10942910902894898.

Rodriguez-Amaya, D. B. (2016). Natural food pigments and colorants. Current Opinion in Food Science, 7, 20-26. https://doi.org/10.1016/j.cofs.2015.08.004.

Santillán-Urquiza, E., Méndez-Rojas, M.Á., \& Vélez-Ruiz, J. F. (2017). Fortification of yogurt with nano and micro sized calcium, iron and zinc, effect on the physicochemical and rheological properties. Lebensmittel-Wissenschaft und -Technologie- Food Science and Technology, 80, 462-469. https://doi.org/10.1016/j.lwt.2017.03.025.

Spence, C., Levitan, C. A., Shankar, M. U., \& Zampini, M. (2010). Does food color influence taste and flavor perception in humans? Chemosensory Perception, 3(1), 68-84. https://doi.org/10.1007/s12078-010-9067-z.

Suantawee, T., Cheng, H., \& Adisakwattana, S. (2016). Protective effect of cyanidin against glucose- and methylglyoxal-induced protein glycation and oxidative DNA damage. International Journal of Biological Macromolecules, 93, 814-821. https://doi. org/10.1016/j.ijbiomac.2016.09.059.

Takeda, K., Harborne, J. B., \& Self, R. (1986). Identification and distribution of malonated anthocyanins in plants of the compositae. Phytochemistry, 25(6), 1337-1342.

Takeda, K., Kumegawa, C., Harborne, J. B., \& Self, R. (1988). Pelargonidin 3-(6"-succinyl glucoside)-5-glucoside from pink Centaurea cyanus flowers. Phytochemistry, 27(4), 1228-1229.

Takeda, K., Osakabe, A., Saito, S., Furuyama, D., Tomita, A., Kojima, Y., et al. (2005). Components of protocyanin, a blue pigment from the blue flowers of Centaurea cyanus. Phytochemistry, 66(13), 1607-1613. https://doi.org/10.1016/j.phytochem. 2005.04.002.

Takeda, K., \& Tominaga, S. (1983). The anthocyanin in blue flowers of Centaurea cyanus. Botanical Magazine Tokyo, 96(4), 359-363.

Velioglu, Y. S., \& Mazza, G. (1991). Characterization of flavonoids in petals of Rosa damascena by HPLC and spectral analysis. Journal of Agricultural and Food Chemistry, 39(3), 463-467.

Wu, X., \& Prior, R. L. (2005). Identification and characterization of anthocyanins by highperformance liquid chromatography-electrospray ionization-tandem mass spectrometry in common foods in the United States: Vegetables, nuts, and grains. Journal of Agricultural and Food Chemistry, 53(8), 3101-3113. https://doi.org/10.1021/ 
jf0478861.

Yamaguchi, M.-A., Oshida, N., Nakayama, M., Koshioka, M., Yamaguchi, Y., \& Ino, I. (1999). Anthocyanidin 3-glucoside malonyltransferase from Dahlia variabilis.

Phytochemistry, 52(1), 15-18. https://doi.org/10.1016/S0031-9422(99)00099-0. Yang, L., Dykes, L., \& Awika, J. M. (2014). Thermal stability of 3-deoxyanthocyanidin pigments. Food Chemistry, 160, 246-254.
Zielinski, A. A. F., Haminiuk, C. W. I., Alberti, A., Nogueira, A., Demiate, I. M., \& Granato, D. (2014). A comparative study of the phenolic compounds and the in vitro antioxidant activity of different Brazilian teas using multivariate statistical techniques. Food Research International, 60, 246-254. https://doi.org/10.1016/j.foodres.2013.09. 010. 